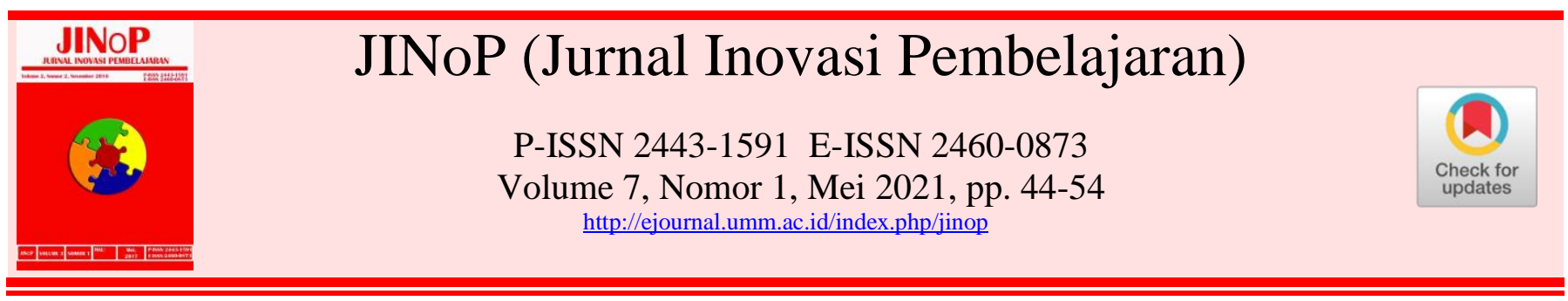

\title{
Pengembangan buku ajar mata kuliah belajar dan pembelajaran berbasis moodle
}

\author{
Anangga Widya Pradipta ${ }^{1)^{*}}$, Rubbi Kurniawan ${ }^{2)}$ \\ ${ }^{1}$ Prodi Pendidikan Jasmani Kesehatan dan Rekreasi Fakultas Pendidikan Ilmu Eksata dan Keolaharagaan \\ IKIP Budi Utomo, Jl. Simpang Arjuno No.14.B, Kota Malang, Indonesia \\ ${ }^{2}$ Prodi Pendidikan Jasmani Kesehatan dan Rekreasi Fakultas Pendidikan Ilmu Eksata dan Keolaharagaan \\ IKIP Budi Utomo, Jl. Simpang Arjuno No.14.B, Kota Malang, Indonesia
}

ananggawidya@budiutomomalang.ac.id*; rubbikurniawan@budiutomomalang.ac.id

* Penulis Koresponden

ABSTRAK
Belajar dan pembelajaran adalah mata kuliah yang memerlukan kemampuan analisis yang tinggi,
waktu yang lebih fleksibel dan media pembelajaran yang mendukung untuk belajar. Salah satu
media pembelajaran yang digunakan pada mata kuliah belajar dan pembelajaran adalah buku ajar.
Penelitian ini bertujuan untuk mendesain dan mengembangkan buku ajar mata kuliah belajar dan
pembelajaran berbasis MOODLE. Penelitian menggunakan metode R\&D jenis ADDIE. Subjek
penelitian yaitu mahasiswa Prodi PJKR IKIP Budi Utomo yang sedang menempuh mata kuliah
belajar dan pembelajaran pada semester II tahun akademik 2019-2020. Instrumen yang digunakan
berupa angket untuk mengetahui kelayakan buku ajar dan tes untuk mengetahui hasil belajar
mahasiwa setelah belajar menggunakan buku ajar berbasis MOODLE. Penilaian standar isi dari
ahli media sebesar 57 dengan persentase sebesar 95\% kriteria sangat baik dan tanpa revisi.
Penilaian standar visual dari ahli media yaitu sebesar 61 dengan persentase sebesar 94\% kriteria
sangat baik dan tanpa revisi. Penilaian standar isi dari ahli materi sebesar 48 dengan persentase
sebesar $80 \%$ kriteria sangat baik dan tanpa revisi. Penilaian standar visual dari ahli materi yaitu
sebesar 53 dengan persentase sebesar $82 \%$ kriteria sangat baik dan tanpa revisi. Efektifiats buku
ajar (N-gain) sebesar 0.52 pada kriteria sedang.
Kata Kunci: Buku Ajar; Belajar dan Pembelajaran; MOODLE.

\section{ABSTRACT}

Belajar dan Pembelajaran (learning and teaching learning) requires high analytical skills, flexible time, and supporting learning media, one of which is books. This research aims to design and develop teaching books for Belajar dan Pembelajaran that are MOODLE-based. This research employed Research and Development (R\&D) method with the ADDIE technique. Participants of this research are second-semester students of the PJKR IKIP Budi Utomo Program (the year 2019-2020) who took the Belajar dan Pembelajaran course. Questionnaire technique was employed to determine the feasibility of teaching books, and to test student learning outcomes after using MOODLE-based teaching books. The standard assessment of content from media experts is 57 with a percentage of $95 \%$, referring to very good criteria without revision. The visual standard assessment from media experts is 61 with a percentage of $94 \%$, referring to very good criteria without revision. The content standard assessment from material experts is 48 with a percentage of $80 \%$, referring to very good criteria without revision. The visual standard assessment from material experts is 53 with a percentage of $82 \%$, referring to very good criteria without revision. Teaching books' effectiveness ( $\mathrm{N}$-gain) is 0.52 on moderate criteria.

Keywords: Teaching Book; Belajar dan Pembelajaran; MOODLE

diunggah: 2020-09-28, direvisi: 2020-12-05, diterima: 2020-12-07, dipublikasi: 2021-05-21

Copyright (c) 2021 Pradipta et al

This is an open access article under the CC-BY license 
Cara sitasi: Pradipta, A. W., \& Kurniawan, R. (2021). Pengembangan buku ajar mata kuliah belajar dan pembelajaran berbasis moodle. JINoP (Jurnal Inovasi Pembelajaran), 7(1), 44-55. https://doi.org/10.22219/jinop.v7i1.13856

\section{PENDAHULUAN}

Modernisasi dan perkembangan zaman yang semakin pesat telah mengubah pola persaingan yang semakin ketat. Sistem persaingan telah beralih dari tujuan untuk lebih unggul dari individu yang lain menjadi memaksimalkan potensi yang dimiliki melalui pendidikan dan pelatihan kerja yang tekualifikasi secara nasional. Khusus di negara ASEAN persaingan tersebut tampak dalam penguasaan ilmu pengetahun dan teknologi dan ketersediaan lapangan pekerjaan.

Hal ini mengakibatkan negara Indonesia menyusun Kerangka Kualifikasi Nasional Indonesia (KKNI) sebagai penyeimbang persaingan tersebut (Setiawan, 2017). Tujuan utamanya yaitu agar sumber daya manusia Indonesia setara dengan sumber daya manusia dibelahan benua yang lainnya terutama negara negara maju dalam bidang pendidikan dan pelatihan kerja diberbagai sektor (Rahman, 2019). KKNI merupakan kurikulum yang menitik beratkan kompetensi atau learning outcomes sehingga kemampuan dan keterampilan tertanam melalui materi mata kuliah dengan tujuan menyelaraskan, menyandingkan, dan mengintegrasikan keterampilan dan pasar kerja (Nurdin, 2018) (Siagian \& Siregar, 2018) (Murtikusuma, Fatahillah, \& Monalisa, 2017).

Kerangka Kualifikasi Nasional Indonesia menjadikan institusi pendidikan melakukan pembaharuan terhadap proses belajar mengajar yang berdampak pada sajian capaian pembelajaran mata kuliah (Waseso \& Hidayat, 2017) (Ulfa \& Yulianto, 2019). Salah satu cara penyajiannya dapat dilakukan dengan mengintegrasikan teknologi informasi dan komunikasi dalam bentuk lingkungan belajar yang dinamis untuk dapat melaksanakan aktivitas belajar yang optimal (Kirom, 2017). Lingkungan belajar yang dinamis dapat tercipta jika komponen pembelajaran yang terdiri dari pesan, orang, bahan, teknik dan lingkungan dapat berjalan secara dinamis tanpa mengenal batasan ruang dan waktu (Wiyono, Muis, \& Khusumadewi, 2018).

Mata kuliah Belajar dan Pembelajaran merupakan mata kuliah wajib pada program studi Pendidikan Jasmani Kesehtan Rekreasi (PJKR). Mata kuliah ini merupakan mata kuliah wajib 3 SKS teori yang bertujuan yang memiliki capaian pembelajaran mata kuliah mampu menganalisis permasalhan terkait penerapan teori belajar dalam pembelajaran. Sesuai karakteristik mata kuliah tersebut memerlukan kemampuan analisis yang tinggi, waktu yang lebih fleksibel dan media pembelajaran yang mendukung untuk belajar.

Pada tahun 2018, mata kuliah ini telah memiliki lingkungan pembelajaran dinamis dalam bentuk Learning Management System (LMS) yang selanjutnya dikenal dengan $E$ Learning berbasis MOODLE (Modular Object Oriented Dynamic Learning Environment) (Herayanti, Fuaddunnazmi, \& Habibi, 2017) (Irawan \& Surjono, 2018). Penggunaan E-Learning adalah alternatif untuk menyelenggarakan pembelajaran yang tidak terbatas tempat dan waktu, sehingga hasil belajar diharapkan lebih optimal (Khoir, Murtinugraha, \& Musalamah, 2020) (Maulana, 2020). E-learning ini tersedia secara online melalui laman https://widyapradipta.com selanjutnya dilakukan take down dan dilakukan instalasi ulang pada laman server Virtual Personal Server (VPS) dengan perangkat penunjuk http://103.247.11.240/ masa aktif server hingga 10 September 2021. E-learning ini telah terukur dari standar teknis maupun visual (Pradipta \& Wardathi, $\underline{2018)}$.

Kekurangan dari E-learning ini yaitu belum mempunyai buku ajar yang dikembangkan sesuai dengan kebutuhan mata kuliah. Dalam bidang pendidikan, buku 
Pradipta et.al - JINoP (Jurnal Inovasi Pembelajaran) Vol. 7(1) 2021

ajar memiliki kaitan erat dengan proses pembelajaran dan kurikulum (Suwartini, 2018). Kesalahan dalam pemilihan buku ajar berpengaruh negatif terhadap tujuan belajar maupun hasil belajar (R, Amir, Yusri, \& Anwar, 2019). Buku ajar merupakan sarana bagi keterlaksanaan pendidikan dan pembelajaran (Surahman \& Yeni, 2019). Sifat dari buku ajar yaitu sebagai pendamping fasilitator saat pembelajaran berlangsung (Adalikwu \& Iorkpilgh, 2013) berpendapat bahwa buku ajar memiliki peran sebagai fasilitator antara pendidik dengan peserta didik selama pembelajaran berlangsung.

Sesuai dengan observasi yang dilakukan saat pembelajaran mata kuliah belajar dan pembelajaran, diperoleh informasi bahwa lebih dari $30 \%$ mahasiswa belum berpartisipasi secara aktif dalam perkuliahan baik secara tatap muka maupun daring karena belum ada buku ajar yang digunakan sebagai acuan pembelajaran. Buku ajar yang belum tersedia menjadikan mahasiswa belum siap mengikuti perkuliahan karena mahasiswa belum mempelajari materi.

Berdasar angket kebutuhan bahan ajar yang diberikan, mahasiswa menginginkan pengadaan bahan ajar yang dikembangkan oleh dosen dengan substansi isi sesuai dengan rencana program pembelajaran. Jenis bahan ajar yang diinginkan mahasiswa yaitu $60.56 \%$ menginginkan disusunnya buku ajar mata kuliah belajar dan pembelajaran.

Buku ajar merupakan bagian penting dalam pembelajaran karena digunakan sebagai salah satu sumber belajar pada mata kuliah tertentu (Kurniawan \& Masjudin, 2018). Karakter buku ajar memiliki perbedaan dengan buku teks pada umumnya. Perbedaan tersebut terletak pada perancangan dan pengembangannya yang disesuaikan dengan kurikulum berdasarkan kebutuhan mahasiswa, penggunaan bahasa yang komunikatif, disusun untuk pembelajaran serta memiliki umpan balik dari peserta didik. (Prastowo, 2012) berpendapat bahwa buku ajar merupakan buku yang berisi ilmu pengetahuan dan disusun atas dasar kompetensi yang harus dikuasai dalam kurikulum tertentu serta digunakan oleh peserta didik untuk belajar. Buku ajar ini merupakan hasil pengembangan dari penelitian yang berjudul "Pengembangan E-Learning Berbasis MOODLE v.3.1. pada Mata Kuliah Belajar dan Pembelajaran" yang dilakukan pada tahun 2018 (Pradipta \& Wardathi, 2018)

Keterbaruan pengembangan buku ajar mata kuliah belajar dan pembelajaran berbasis $M O O D L E$ yaitu dengan menggabungkan pengembangan buku ajar sebagai bahan ajar cetak dengan aplikasi MOODLE sehingga memiliki keunggulan dalam penggunaannya. Keunggulan pertama yaitu aplikasi ini merupakan fitur gratis dengan sumber terbuka sehingga pengguna dan administrator bebas menjalankan, membagikan, dan mengubahnya. Keunggulan kedua yaitu pengguna dapat mengunduh dan mengakses aplikasi pada perangkat pengguna secara offline. Keunggulan ketiga aplikasi ini yaitu memiliki tampilan sederhana sehingga mudah digunakan dan dijalankan pada mesin telusur dan memiliki konsumsi transfer data internet yang rendah.

Berdasarkan kebutuhan buku ajar, ketersediaan dan keunggulan aplikasi MOODLE, maka tujuan penelitian yang dilakukan yaitu untuk mendesain dan mengembangkan buku ajar mata kuliah belajar dan pembelajaran berbasis MOODLE. Buku ajar yang dikembangkan diharapkan mampu memberikan kontribusi dalam pemenuhan sumber belajar berbentuk bahan ajar cetak berupa buku ajar yang memiliki sifat pembelajaran dinamis yang mampu mengatasi keterbatasan ruang dan waktu dalam pelaksanaan pembelajaran di kelas.

Spesifikasi produk yang diharapkan yaitu buku ajar mata kuliah belajar dan pembelajaran berbasis MOODLE. Spesifikasi buku ajar sesuai dengan standar penulisan buku ajar Kementerian Riset dan Teknologi Pendidikan Tinggi (Pengelolaan Kekayaan Intelektual, Direktorat Jenderal Penguatan Riset dan Pengembangan, \& Kementerian Riset, Teknologi, dan Pendidikan Tinggi, 2018) yaitu: 1) prakata; 2) daftar isi; 3) batang tubuh yang terbagi dalam bab atau bagian; 4) daftar pustaka; 5) glosarium; 6) indeks. 
Ukuran buku A5 (14,8 cm X $21 \mathrm{~cm})$. Batang tubuh terdiri dari teori belajar dan penerapan: 1) Teori belajar secara deskriptif dan Preskriptif; 2) Teori Belajar Behavioristik; 3) Teori Belajar Kognitif; 4) Teori Belajar Konstruktivistik; 5) Teori Belajar Humanistik; 6) Teori Belajar Sibernetik; 7) Teori Belajar Revolusi-Sosiokultural; 8) Teori Belajar Kecerdasan Ganda.

\section{METODE}

Penelitian ini berjenis $R \& D$ Langkah yang ditempuh menggunakan prosedur pengembangan (Research and Development) tipe ADDIE. Model ini merupakan model pengembangan desain sistem pembelajaran yang sederhana yang terdiri dari 5 fase yaitu analysis, design, development, Implementation, evaluation (Januszewski \& Molenda, 2008).

Langkah langkah penelitiannya terdiri dari Analysys, Design, Development, Implementation and evaluation. Analysis berupa analisis instruksional dan analisis sumber. Design terdiri dari menyusun bahan pembelajaran, menyusun standar rancangan program $L M S$ pendamping buku ajar, merancang tugas, merancang diskusi dan merancang kuis. Development berupa kegiatan validasi produk, uji kelompok kecil dan besar hingga revisi. Implementation berupa penerapan buku ajar mata kuliah belajar dan pembelajaran dengan bahan pendamping LMS. Evaluation berbentuk evaluasi formatif untuk kebutuhan revisi.

Penelitian dilakukan di IKIP Budi Utomo Malang. Subjek penelitian mahasiswa Prodi PJKR. Waktu Penelitian pada semester II tahun 2019-2020. Sumber data dalam penelitian yang dilakukan adalah hasil pemberian angket dan skor pemberian tes pemahaman kosep mata kuliah belajar dan pebelajaran. Sumber data dalam penelitian ini adalah mahasiswa Semester II IKIP Budi Utomo Malang tahun 2019-2020. Penelitian ini dilaksanakan dengan izin lembaga Penelitian dan Pengabdian kepada Masyarakat (P2M) dengan surat Izin penelitian Nomor :123/IKIP-BU/P2M/IV/2020 dengan surat tugas penelitian Nomor :124/IKIP-BU/P2M/IV/2020 terhitung mulai 27 Maret 2020 sampai dengan 20 Oktober 2020.

Teknik Pengumpulan data yang dilakukan terdiri dari angket dan tes pemahaman konsep. Angket digunakan untuk mendapatkan data tentang kelayakan kualitas buku ajar mata kuliah belajar dan pembelajaran berbasis MOODLE. Penyusunan kuesioner dilakukan menggunakan kisi-kisi tervalidasi dari expert judgement.

Soal tes digunakan mengukur tingkat hasil belajar mahasiswa terhadap materi ajar setelah belajar menggunakan buku ajar berbasis MOODLE. Soal tes berupa pre-test dan post-test yang sama namun diberikan pada pwaktu yang berbeda. Jenis soal tes yaitu pilihan ganda dengan 5 alternatif jawaban yang memiliki 1 jawaban paling benar dan paling tepat. Instrumen tes terdiri dari 50 butir soal. Sesuai dengan pendapat Sudjana (2013: 35-48), tes pada umumnya digunakan untuk mengukur hasil belajar kognitif berkenaan dengan penguasaan bahan pengajaran sesuai dengan tujuan pendidikan dan pengajaran.

Validitas isi dilakukan dengan judgement expert. Hasil judgement expert kemudian dianalisis menggunakan product moment (Sugiyono, 2013). Sedangkan untuk reliabilitas instrument kuesioner dilakukan menggunakan sajian data asli yang memenuhi tiga aspek yaitu mantap, handal dan terprediksi (Sudjana, 2013). Khusus untuk test hasil belajar dianalisis secara statistik. Reliabilitas instrumen pemahaman konsep dilakukan dengan foemula KR-20.

Perolehan data dianalisis secara deskriptif melalui sajian rerata pencapaian hasil belajar. Hasil analisis data deskriptif kuantitatif kemudian dimaknai secara kualitatif 
Tabel 1. Kriteria Penilaian Ideal Uji Media Standar Teknis dan Standar Visual Buku Ajar Mata Kuliah Belajar dan Pembelajaran Berbasis MOODLE

\begin{tabular}{cc}
\hline Kriteria & Skor \\
\hline Sangat Baik & $80<\mathrm{X}-$ \\
Baik & $64<\mathrm{X} \leq 80$ \\
Cukup & $48<\mathrm{X} \leq 64$ \\
Kurang & $32<\mathrm{X} \leq 48$ \\
Sangat Kurang & $\mathrm{X} \leq 32$ \\
\hline
\end{tabular}

Tabel 2. Kriteria Penilaian Ideal Hasil Belajar Menggunakan Buku Ajar Mata Kuliah Belajar dan Pembelajaran Berbasis MOODLE

\begin{tabular}{cc}
\hline Kriteria & Skor \\
\hline Sangat Baik & $79,5<\mathrm{X}-$ \\
Baik & $75,5<\mathrm{X} \leq 80$ \\
Cukup & $71,5<\mathrm{X} \leq 75,5$ \\
Kurang & $67,5<\mathrm{X} \leq 71,5$ \\
Sangat Kurang & $\mathrm{X} \leq 67,5$ \\
\hline
\end{tabular}

Perolehan data tes hasil belajar mahasiswa digunakan untuk mengetahui efektifitas produk pembelajaran. (Meltzer, 2002) berpendapat bahwa skor nilai gain dihitung untuk mengetahui efektifitas perlakuan yang diberikan.

\section{HASIL DAN PEMBAHASAN}

Hasil pelaksanaan penelitian berupa pelaksanaan langkah langkah penelitian sesuai dengan metode penelitiaan ADDIE. Tahapan tersebut terdiri dari Analysis, Design, Development, Implementation dan Evaluation.

Tahap pertama yaitu Analysis, berupa identifikasi dan mengembangkan pemahaman yang jelas tentang kebutuhan mahasiswa. Tahapan ini terdiri dari: 1) Analisis Tujuan pembelajaran; 2) Analisis sumber belajar.

Analisis instruksional menurut (Dick \& Carey, 2001) adalah suatu penerapan prosedur identifikasi kemampuan-kemampuan bawahan (sub-ordinate skills) yang diperlukan untuk mencapai tujuan instruksional. Berdasarkan pendapat tersebut, analisis instruksional yang dilakukan berupa proses penjabaran perilaku umum ke perilaku khusus. Jabaran perilaku umum berupa penentuan Capaian Pembelajaran Mata Kuliah (CPMK) sedangkan jabaran perilaku khusus berupa Sub-Capaian Pembelajaran Lulusan (Sub-CPMK) yang dibebankan pada mata kuliah yang selanjutnya mengembangkan matrik pembelajaran semester (MPS) dan Rencana Program Pembelajaran Semester (RPPS)

Capaian Pembelajaran Mata Kuliah (CPMK) Belajar dan Pembelajaran diharapkan Setelah menempuh mata kuliah belajar dan pembelajaran, mahasiswa diharapkan bukan hanya mampu mengetahui konsep belajar dan pembelajaran tetapi juga mampu memahami berbagai bentuk penerapan teori belajar pada pembelajaran. Sub-Capaian Pembelajaran Mata Kuliah (Sub-CPMK) Belajar dan Pembelajaran terdiri dari: 1) Menganalisis perbedaan teori deskriptif dan teori preskriptif; 2) Menganalisis penerapan Teori Belajar Behavioristik dalam pembelajaran; 3) Menganalisis penerapan Teori Belajar Kognitif dalam pembelajaran; 4) Menganalisis penerapan Teori Belajar Konstruktivistik dalam pembelajaran; 5) Menganalisis penerapan Teori Belajar 
Humanistik dalam pembelajaran; 6) Menganalisis penerapan Teori Belajar Sibernetik dalam pembelajaran; 7) Menganalisis penerapan Teori Belajar Revolusi-Sosiokultural dan penerapannya dalam pembelajaran; 7) Menganalisis penerapan Teori Belajar Revolusi-Sosiokultural dalam pembelajaran; 8) Menganalisis penerapan Teori Belajar Kecerdasan Ganda dalam pembelajaran.

Berdasarkan analisis sumber belajar untuk mata kuliah belajar dan pembelajaran terdiri dari: buku teks dan website sebagai bahan belajar. Alat (media pembelajaran) yang digunakan yaitu power point yang ditampilkan melaui Smart TV. Orang yaitu dosen sebagai pengajar dan mahasiswa sebagai peserta belajar. Bahan belajar yang digunakan yaitu slide power point yang berisi ringkasan materi perkuliahan. Dalam pelaksanaannya menggunakan pendekatan yang berpusat pada mahasiswa berupa strategi pemecahan masalah. Lingkungan belajar yang digunakan yaitu ruang kelas, perpustakaan yang dimiliki Program Sudi Pendidikan Jasmani Kesehatan dan Rekreasi serta ditunjang adanya LMS

Berdasarkan analisis instruksional dan analisis sumber belajar yang telah dilakukan, mata kuliah belajar dan pembelajaran telah memiliki sumber belajar yang memadai namun memiliki kekurangan dari segi bahan pembelajaran. Sisi kurang tersebut yaitu belum menggunakan buku ajar yang disesuaikan dengan kebutuhan pembelajaran mata kuliah belajar dan pembelajaran pada program studi PJKR.

Tahap kedua yaitu Design merupakan tahap pengembangan ide-ide, melakukan analisis konsep dan tugas, dan melakukan deskripsi produk awal. Pada tahap ini dilakukan beberapa yaitu melakukan desain buku ajar dan desain LMS MOODLE. Desain buku ajar tahap ini yaitu menghasilkan draf buku ajar cetak terdiri dari cover (halaman sampul), prakata, daftar isi, petunjuk penggunaan, dan capaian pembelajaran pada tiap bab. Isi buku terdiri dari 8 BAB. Sampul buku menggunakan warna dasar biru sebagai identitas IKIP Budi Utomo Malang. Sampul depan berisi judul buku, nama pengarang, dan nama institusi. Sampul buku bagian belakang berisi uraian singkat terkait buku ajar mata kuliah belajar dan pembelajaran yang dikembangkan. Baik sampul buku maupun isi buku mempunyai ukuran yang sama yaitu dengan standar ukuran B5 sebesar 17.6 Cm X 25.0 $\mathrm{Cm}$. Sajian materi dalam buku ajar dirancang untuk memberdayakan kemampuan analisis dan penerapan konsep melalui pembelajaran yang kreatif. Sajian materi disusun secara terstruktur dari yang sederhana hingga kompleks. Stimulasi pemberdayaan kemampuan analisis menggunakan langkah-langkah Guided Discovery Learning. Tahap-tahap penerapan belajar penemuan, yaitu; 1) stimulus (pemberian perangsang/stimuli), 2) problem statement (mengidentifikasi masalah), 3) data collection (pengumpulan data), 4) data processing (pengolahan data), 5) verifikasi, dan 6) generalisasi”.

Desain Learning Management System (LMS) berbasis MOODLE sebagai lingkungan virtual yaitu mengembangkan bahan pembelajaran berupa penentuan tujuan dan sasaran, merancang kerangka materi, memilih bahan, urutan bahan dari termudah sampai paling sulit, dan mengidentifikasi berbagai referensi. Adapun materi yang akan dijadikan bahan penyerta $M O O D L E$ yaitu yang sesuai dengan kebutuhan mahasiswa yang tersaji pada alamat internet protokol server http://103.247.11.240/ masa aktif VPS hingga tanggal 10 September 2021 (hubungi admin jika akan mengakses).

Tahap ketiga adalah kegiatan pengembangan (development) yang meliputi kegiatan penyusunan buku ajar berbasis MOODLE. Kegiatan pengumpulan bahan/materi, pembuatan gambar-gambar, pengetikan, dan sebagainya merupakan kegiatan pada tahap pengembangan ini.

Pada tahap ini mengumpulkan dan menyusun materi yang disajikan dalam buku ajar berbasis MOODLE. Materi disusun menggunakan bahasa yang sederhana agar mudah untuk dipahami. 
Setelah tahap pengembangan buku ajar, selanjutnya dilakukan pengujian aplikasi $L M S$ oleh para ahli yang melibatkan satu orang ahli materi mata kuliah belajar dan pembelajaran, satu orang ahli media dan desain pembelajaran dan selanjutnya dilakukan uji keterbacaaan oleh mahasiswa.

Penilaian ahli materi diajukan kepada Praharisti Kurniasari, M.Pd selaku ahli materi mata kuliah belajar dan pembelajaran dari IKIP Budi Utomo Malang untuk menilai Standar Teknis dan isi buku ajar mata kuliah belajar dan pembelajaran berbasis MOODLE. Hasil penilaian sebagai berikut:

Tabel 4. Hasil Penilaian Ahli Media terhadap Pengembangan Buku Ajar Mata Kuliah Belajar dan Pembelajaran Berbasis MOODLE

\begin{tabular}{llccccc}
\hline No. & Aspek & $\begin{array}{c}\text { Jumlah } \\
\text { Indikator }\end{array}$ & $\begin{array}{c}\text { Skor } \\
\text { Maksimal }\end{array}$ & $\begin{array}{c}\text { Skor } \\
\text { Validasi }\end{array}$ & $\begin{array}{c}\text { Persen } \\
\text { tase (\%) }\end{array}$ & Kriteria \\
\hline 1 & Standar Isi & 12 & 60 & 57 & 95 & Sangat baik dan Tidak perlu revisi \\
2 & Standar Visual & 13 & 65 & 61 & 94 & Sangat baik dan Tidak perlu revisi \\
\hline
\end{tabular}

Tabel 5. Hasil Penilaian Ahli Materi terhadap Pengembangan Buku Ajar Mata Kuliah Belajar dan Pembelajaran Berbasis MOODLE

\begin{tabular}{llccccc}
\hline No. & Aspek & $\begin{array}{c}\text { Jumlah } \\
\text { Indikator }\end{array}$ & $\begin{array}{c}\text { Skor } \\
\text { Maksimal }\end{array}$ & $\begin{array}{c}\text { Skor } \\
\text { Validasi }\end{array}$ & $\begin{array}{c}\text { Persentase } \\
\text { (\%) }\end{array}$ & Kriteria \\
\hline 1. & Standar Isi & 12 & 60 & 48 & 80 & Baik dan tidak perlu revisi \\
2. & Standar Visual & 13 & 65 & 53 & 82 & Sangat baik dan Tidak perlu revisi \\
\hline
\end{tabular}

Data deskriptif merupakan saran dan masukan ahli materi mata kuliah belajar dan pembelajaran dalam lembar validasi mengenai bahan ajar Belajar dan pembelajaran meliputi: 1) Menggunakan huruf capital setelah angka/titik; 2) Font papada kata berbahasa inggris mohon diperhatikan ulang; Komentar dan Saran dari ahli media 1) gunakan bahasa Indonesia agar mudah dipahami; 2) Menggunakan kata/kalimat yang lebih tepat. Jumlah validator ahli materi dan media disarankan lebih dari satu orang agar memperoleh lebih banyak saran serta perbaikan buku ajar. Hendaknya penelitian dilanjutkan pada uji kelompok besar agar memperoleh lebih banyak saran dan perbaikan.

Setelah mendapatkan penilaian dari ahli materi dan media pembelajaran maka dilakukan uji kelompok kecil penggunaan buku ajar tersebut terhadap 10 orang mahasiswa. Hasil penilaian uji kelompok kecil sebagai berikut:

Tabel 6. Hasil Penilaian Standar Isi Uji Kelmpok Kecil Buku Ajar Mata Kuliah Belajar dan Pembelajaran Berbasis MOODLE

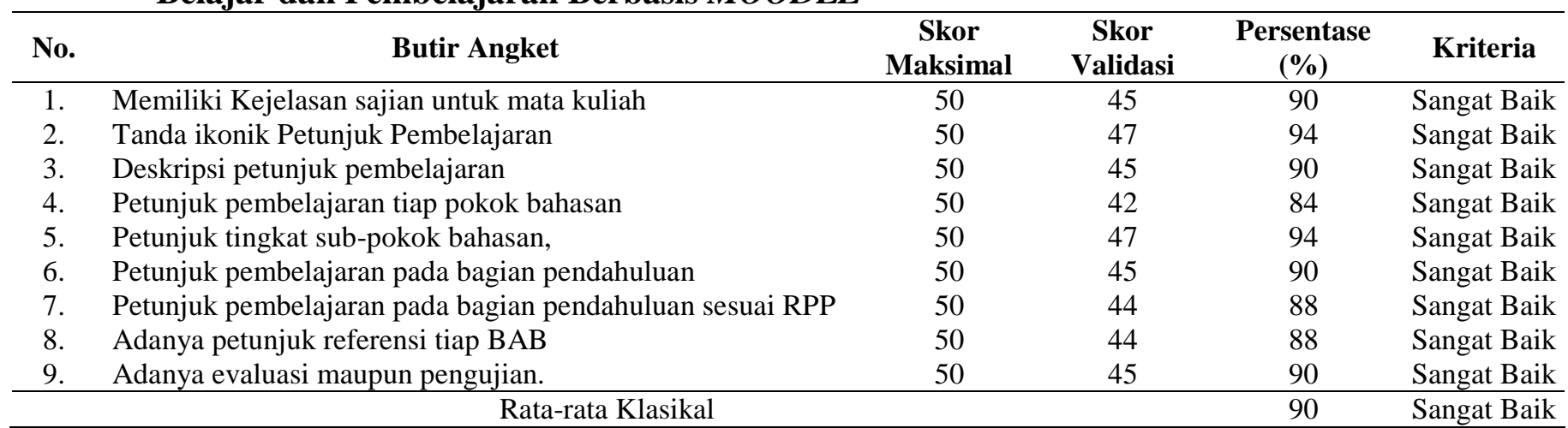


Tabel 7. Hasil Penilaian Visual Uji Kelmpok Kecil Buku Ajar Mata Kuliah Belajar dan Pembelajaran Berbasis MOODLE

\begin{tabular}{|c|c|c|c|c|c|}
\hline No. & Butir Angket & $\begin{array}{c}\text { Skor } \\
\text { Maksimal }\end{array}$ & $\begin{array}{c}\text { Skor } \\
\text { Validasi }\end{array}$ & $\begin{array}{c}\text { Persentase } \\
(\%)\end{array}$ & Kriteria \\
\hline 1. & Penggunaan lambang atau logo institusi & 50 & 45 & 90 & Sangat Baik \\
\hline 2. & Setiap halaman memuat logo buku ajar & 50 & 46 & 92 & Sangat Baik \\
\hline 3. & Konsistensi penggunaan ikon & 50 & 45 & 90 & Sangat Baik \\
\hline 4. & $\begin{array}{l}\text { Ikon diberikan keterangan atau menggunakan } \\
\text { simbol yang sudah umum digunakan }\end{array}$ & 50 & 42 & 84 & Sangat Baik \\
\hline 5. & $\begin{array}{l}\text { Semua objek dalam buku diberi keterangan atau } \\
\text { kesan bahwa objek tersebut berisi informasi. }\end{array}$ & 50 & 47 & 94 & Sangat Baik \\
\hline 6. & $\begin{array}{l}\text { Menggunakan penomoran yang konsisten untuk } \\
\text { mengidentifikasi langkah - langkah yang } \\
\text { dilakukan dalam penggunaan konten }\end{array}$ & 50 & 44 & 88 & Sangat Baik \\
\hline 7. & $\begin{array}{l}\text { Pengaturan dilakukan secara rapi sehingga tidak } \\
\text { menggangu dalam pemakaian / pembacaan } \\
\text { konten }\end{array}$ & 50 & 42 & 84 & Sangat Baik \\
\hline 8. & $\begin{array}{l}\text { Kombinasi warna tulisan, gambar, background } \\
\text { tidak mengganggu pembaca }\end{array}$ & 50 & 45 & 90 & Sangat Baik \\
\hline 9. & Fokus materi adalah isi pembelajaran. & 50 & 45 & 90 & Sangat Baik \\
\hline 10. & $\begin{array}{l}\text { Menghindari objek tertentu yang dapat } \\
\text { mengalihkan perhatian pengguna, sehingga } \\
\text { upengguna fokus materinya, }\end{array}$ & 50 & 46 & 92 & Sangat Baik \\
\hline 11. & $\begin{array}{l}\text { Teks diorganisasi dalam paragraf yang mudah } \\
\text { dibaca }\end{array}$ & 50 & 45 & 90 & Sangat Baik \\
\hline 12. & $\begin{array}{l}\text { Ejaan dan terminology digunakan dengan benar } \\
\text { dan konsisten }\end{array}$ & 50 & 45 & 90 & Sangat Baik \\
\hline 13. & $\begin{array}{l}\text { Secara umum, cover dan pewarnaan } \\
\text { mencerminkan warna atau identitas IKIP Budi } \\
\text { Utomo Malang }\end{array}$ & 50 & 45 & 90 & Sangat Baik \\
\hline \multicolumn{4}{|c|}{ Rata-rata Klasikal } & 89,54 & Sangat Baik \\
\hline
\end{tabular}

Tabel 8. Hasil Belajar Menggunakan Buku Ajar Mata Kuliah Belajar dan Pembelajaran Berbasis MOODLE

\begin{tabular}{cccc}
\hline No. & Inisial Nama & Nilai & Kriteria \\
\hline 1 & BKU & 85 & Sangat Baik \\
2 & AAB & 80 & Sangat Baik \\
3 & ODA & 85 & Sangat Baik \\
4 & DAA & 75 & Cukup \\
5 & BB & 85 & Sangat Baik \\
6 & AB & 70 & Kurang \\
7 & YB & 80 & Sangat Baik \\
8 & TC & 80 & Sangat Baik \\
9 & YF & 80 & Sangat Baik \\
10 & RF & 75 & Cukup \\
\hline \multicolumn{4}{r}{}
\end{tabular}

Tahap ke-empat yaitu Implementation. Tahap ini dilakukan setelah mendapatkan validasi dan dinyatakan layak sebagai buku ajar berbasis $M O O D L E$, maka dilakukan implementasi dalam skala yang lebih besar di tahun 2021 semester genap pada mahasiswa yang akan menempuh mata kuliah belajar dan pembelajaran.

Tahap ke-lima yaitu evaluasi. Tahap ini dilakukan pretest dan postes untuk mengetahui efektifitas penggunaan buku ajar mata kuliah belajar dan pembelajaran berbasis MOODLE. Skor pretes 73,5 dan skor postes 79,5. Selanjutnya dilakukan pengukuran nilai gain yaitu dengan membandingkan selisih nilai postes dan pretes dengan 
Pradipta et.al - JINoP (Jurnal Inovasi Pembelajaran) Vol. 7(1) 2021

selisih skor maksimal dan skor pretes. Setelah dilakukan perhitungan terhadap nilai gain diperoleh nilai gain sebesar 0,52 pada kriteria sedang.

Temuan penelitian sejenis dengan judul Pengembangan Buku Ajar Matakuliah Belajar dan Pembelajaran dalam bidang Informatika untuk Prodi S1 Pendidikan Teknik Informatika Jurusan Teknik Elektro di Universitas Negeri Malang yang dilakukan oleh Muhammad Agung Prayogo (Prayogo, 2018). Penelitian yang telah dilakukan memiliki perbedaan yaitu pada subjek penelitian dan muatan isi materi buku ajar yang lebih dikhususkan untuk pembelajaran mata pelajaran Pendidikan Jasmani Kesehatan dan Olahraga. Perbedaan yang lain yaitu terletak pada pengukuran efektifitas ( $\mathrm{N}$-gain) sehingga memiliki perbedaan dengan penelitian yang telah dilakukan. Perbedaan penelitian memiliki perbedaan antara lain sebagai berikut: 1) penelitian ini telah dilakukan pretes dan postes untuk mengukurnya; 2) karakter buku ajar yang telah disusun memiliki perbedaan yaitu dikhususkan untuk riset pada prototype pembelajaran menggunakan MOODLE dengan asumsi jika terjadi penutupan akun widyapradipta.com maka dapat dilakukan pencadangan dan pemulihan data MOODLE pada local hosting maupun online hosting pada perangkat maupun domain yang lain; 3) Karakter instrumen penelitian yang digunakan memiliki kesamaan dalam metode pengukuran angket ahli materi dan ahli media namun memiliki perbedaan pada butir instrument angket yang digunakan; 4) Instrumen tes pengukuran hasil belajar merupakan butir instrument yang telah melalui validasi baik secara konstruk maupun penilaian ahli materi dengan pengajuan 54 butir soal menghasilkan 50 butir soal disetujui.

\section{SIMPULAN}

Produk yang dihasilkan yaitu buku ajar mata kuliah belajar dan pembelajaran berbasis MOODLE. Secara umum buku ajar ini terdiri dari: 1) prakata; 2) daftar isi; 3) batang tubuh yang terbagi dalam bab atau bagian; 4) daftar pustaka; 5) glosarium; 6) indeks. Batang tubuh terdiri dari teori belajar dan penerapan: 1) Teori belajar secara deskriptif dan Preskriptif; 2) Teori Belajar Behavioristik; 3) Teori Belajar Kognitif; 4) Teori Belajar Konstruktivistik; 5) Teori Belajar Humanistik; 6) Teori Belajar Sibernetik; 7) Teori Belajar Revolusi-Sosiokultural; 8) Teori Belajar Kecerdasan Ganda.

Hasil penilaian dari ahli materi dan ahli media dihitung untuk mengetahui kelayakan buku ajar mata kuliah belajar dan pembelajaran berbasis MOODLE. Perolehan skor dari ahli media dari segi standar isi sebesar 57 dengan persentase sebesar 95\% dengan kriteria sangat baik dan tanpa revisi. Perolehan standar visual dari ahli media sebesar 61 dengan persentase sebesar 94\% kriteria sangat baik dan tanpa revisi.

Perolehan skor dari ahli materi dari segi standar isi sebesar 48 dengan persentase sebesar $80 \%$ dengan kriteria sangat baik dan tanpa revisi. Perolehan standar visual dari ahli materi sebesar 53 dengan persentase sebesar $82 \%$ kriteria sangat baik dan tanpa revisi.

Data deskriptif merupakan saran dan masukan ahli materi mata kuliah belajar dan pembelajaran dalam lembar validasi mengenai bahan ajar belajar dan pembelajaran meliputi: 1) menggunakan huruf kapital setelah angka/titik; 2) font pada kata berbahasa Inggris mohon diperhatikan ulang. Komentar dan Saran dari ahli media 1) gunakan bahasa Indonesia agar mudah dipahami; 2) menggunakan kata/kalimat yang lebih tepat. Ahli materi maupun ahli media hendaknya lebih dari satu orang dan dilanjutkan dengan uji kelompok besar agar memperoleh saran dan perbaikan yang beragam.

Buku ajar mata kuliah Belajar dan Pembelajaran dinyatakan efektif meningkatkan hasil belajar dibuktikkan dengan peningkatan skor pretes dari 73,5 menjadi 79,5 pada nilai postes. Nilai tertinggi saat pre-test yaitu 80 dan nilai saat post-test sebesar 85 . Perolehan nilai efektifitas ( $\mathrm{N}$-gain) sebesar 0,52 pada kriteria sedang 
Saran untuk memanfaatkan buku ajar ini; 1) bagi mahasiswa hendaknya mempelajarinya terlebih dahulu sebelum mengikuti perkuliahan baik tatap muka ataupun daring; 2) Bagi dosen hendaknya melakukan penyesuaian dengan belajar, RPS dan karakter pokok bahasan dan 3) bagi institusi perlu dilakukan evaluasi berkala terkait pemanfaatan buku ajar, sehingga dapat diketahui efektifitas sumber belajar dalam mendukung tujuan akademis.

\section{DAFTAR PUSTAKA}

Adalikwu, S. A., \& Iorkpilgh, I. T. (2013). The Influence of Instructional Materials on Academic Performance of Senior Secondary School Students in Chemistry in Cross River State. Global Journal of Educational Research, 12, 39-45.

Dick, W., \& Carey, L. (2001). The Systemic Design of Instruction. United State: AddisonWesley Educational Publishers Inc.

Herayanti, L., Fuaddunnazmi, M., \& Habibi, H. (2017). Pengembangan Media Pembelajaran Berbasis Moodle pada Mata Kuliah Fisika Dasar. Jurnal Pendidikan Fisika Dan Teknologi, 1(3), 205. https://doi.org/10.29303/jpft.v1i3.260

Irawan, R., \& Surjono, H. D. (2018). Pengembangan E-Learning Berbasis Moodle dalam Peningkatkan Pemahaman Lagu pada Pembelajaran Bahasa Inggris. Jurnal Inovasi Teknologi Pendidikan, 5(1), 1-11. https://doi.org/10.21831/jitp.v5i1.10599

Januszewski, A., \& Molenda, M. (2008). Educational Technology: A Definition with Commentary. New York: Routledge.

Khoir, M. H., Murtinugraha, R. E., \& Musalamah, S. (2020). Pengembangan Media Pembelajaran E-Learning Berbasis Moodle Pada Mata Kuliah Metodologi Penelitian. Jurnal PenSil, 9(1), 54-60. https://doi.org/10.21009/jpensil.v9i1.13453

Kirom, A. (2017). Peran Guru dan Peserta Didik dalam Proses Pembelajaran Berbasis Multikultural. AL MURABBI (Vol. 3). Retrieved from http://jurnal.yudharta.ac.id/ v2/index.php/pai

Kurniawan, A., \& Masjudin, M. (2018). Pengembangan Buku Ajar Micro Teaching Berbasis Praktik untuk Meningkatkan Keterampilan Mengajar Calon Guru. In Prosiding Seminar Nasional Pendidik dan Pengembang Pendidikan Indonesia (Vol. 0, pp. 9-16). Retrieved from http://ejournal.mandalanursa.org/index.php/Semnas/ article/view/166

Maulana, I. (2020). Pengembangan E-Learning Berbasis MOODLE di SMK Al Washliyah Sumbr. Jurnal Media Aplikom, 12(1), 1-12. https://doi.org/10.33488/ 1.ma.2.1.247

Meltzer, D. E. (2002). The Relationship Between Mathematics Preparation and Conceptual Learning Gain in Physics: A Possible Inhidden Variablei in Diagnostic Pretest Scores. :Department of physics and Astronomy,Lowa State University: Ames.

Murtikusuma, R. P., Fatahillah, A., \& Monalisa, L. A. (2017). Pengembangan Rancangan Pembelajaran Matakuliah Kombinatorika Berbasis Kerangka Kualifikasi Nasional Indonesia (KKNI) dan Local Wisdom. Jurnal Edukasi, 4(3), 41. https://doi.org/10.19184/jukasi.v4i3.6300

Nurdin, S. (2018). Pengembangan Kurikulum dan Rencana Pembelajaran Semester (RPS) Berbasis KKNI di Perguruan Tinggi. Al-Fikrah: Jurnal Manajemen Pendidikan, 5(1), 21. https://doi.org/10.31958/jaf.v5i1.813

Pengelolaan Kekayaan Intelektual, Direktorat Jenderal Penguatan Riset dan Pengembangan, \& Kementerian Riset, Teknologi, dan Pendidikan Tinggi, D. (2018). Panduan Pengajuan Usulan Program Intensif Buku Ajar Terbit Tahun 2018. Retrieved from http://simlitabmas.ristekdikti.go.id/kinerja 
Pradipta et.al - JINoP (Jurnal Inovasi Pembelajaran) Vol. 7(1) 2021

Pradipta, A. W., \& Wardathi, A. N. (2018). ANALISIS PROSES PENGEMBANGAN E-LEARNING BERBASIS MOODLE V.3.1. PADA MATA KULIAH BELAJAR DAN PEMBELAJARAN. JINoP (Jurnal Inovasi Pembelajaran), 4(2), 113-122. https://doi.org/10.22219/jinop.v4i2.6576

Prastowo, A. (2012). Panduan Kreatif Membuat Bahan Ajar Inovatif. Jogjakarta: Diva Press.

Prayogo, M. A. (2018). Pengembangan Buku Ajar Matakuliah Belajar dan Pembelajaran dalam bidang Informatika untuk Prodi S1 Pendidikan Teknik Informatika Jurusan Teknik Elektro di Universitas Negeri Malang. Tugas Akhir Jurusan Teknik Elektro - Fakultas Teknik UM. Universitas Negeri Malang, Malang. Retrieved from http://karya-ilmiah.um.ac.id/index.php/TA-Elektro/article/view/72377

R, M., Amir, A., Yusri, Y., \& Anwar, M. (2019). Analisis Kebutuhan Penyusunan Buku Ajar Tata Bahasa Jerman. Eralingua: Jurnal Pendidikan Bahasa Asing Dan Sastra, 3(2). https://doi.org/10.26858/eralingua.v3i2.10062

Rahman, R. A. (2019). Penyusunan Design Kurikulum Berbasis Kkni Pada Program Studi Tadris Bahasa Inggris PTKIN (Studi Kasus Pada Iain Bengkulu dan STAIN Curup). Manhaj: Jurnal Penelitian Dan Pengabdian Masyarakat, 3(2), 51. https://doi.org/10.29300/mjppm.v3i2.2369

Setiawan, D. (2017). Pengembangan Model Kurikulum Berorientasi KKNI di Fakultas Ilmu Sosial Universitas Negeri Medan. JUPIIS: JURNAL PENDIDIKAN ILMUILMU SOSIAL, 9(2), 112. https://doi.org/10.24114/jupiis.v9i2.8239

Siagian, B. A., \& Siregar, G. N. S. (2018). Analisis Penerapan Kurikulum Berbasis KKNI di Universitas Negeri Medan. JURNAL Suluh Pendidikan FKIP-UHN, 5(2), 21-35. Retrieved from https://jsp.uhn.ac.id

Sudjana, N. (2013). Dasar-Dasar Proses Belajar Mengajar. Bandung: Sinar Baru Algensindo.

Sugiyono. (2013). Metode penelitian kombinasi (mixed methods). Bandung: Alfabeta.

Surahman, F., \& Yeni, H. O. (2019). Pengembangan Buku Ajar Mata Kuliah Renang Bagi Mahasiswa Pendidikan Jasmani Kesehatan dan Rekreasi. Journal Sport Area, 4(1), 218-229. https://doi.org/10.25299/sportarea.2019.vol4(1).2413

Suwartini, S. (2018). Pengembagan Buku Ajar Pendidikan Karakter dengan Pendekatan Pembelajaran Berbasis Soft Skill pada Siswa SD Kelas II. Jurnal Educhild: Pendidikan Dan Sosial, 7(2), 102-106. https://doi.org/10.33578/JPSBE.V7I2.6520

Ulfa, M., \& Yulianto, B. (2019). Relevansi Model Kurikulum BOBBIT dalam KKNI Pembelajaran Bahasa dan Sastra Indonesia. BELAJAR BAHASA, 4(2), 169. https://doi.org/10.32528/bb.v4i2.2554

Waseso, H. P., \& Hidayat, M. S. (2017). Penerapan Kurikulum Berbasis KKNI pada Prodi PGMI Unsiq Jawa Tengah. JIP: Jurnal Ilmiah PGMI, 3(1), 33-48. https://doi.org/10.19109/jip.v3i1.1376

Wiyono, B. D., Muis, T., \& Khusumadewi, A. (2018). Pengembangan Blended Learning Mata Kuliah Dinamika Kelompok untuk Mahasiswa Jurusan Bimbingan Dan Konseling. Jurnal Bimbingan Dan Konseling Terapan, 2(2), 168. https://doi.org/10.30598/jbkt.v2i2.375 